\title{
PENGARUH ART THERAPY MENGGAMBAR TERHADAP TINGKAT DEPRESI PADA PASIEN SKIZOFRENIA DI RSJD Dr. RM SOEDJARWADI KLATEN
}

\author{
Ruthy Ngapiyem ${ }^{1}$, Petrus Dwi Asmara ${ }^{2}$ \\ ${ }^{(1,2)}$ STIKES Bethesda Yakkum Jl. Johar Nurhadi No. 6 Yogyakarta 524565 \\ Email: ruthy.gk@gmail.com
}

\begin{abstract}
ABSTRAK
Latar belakang : Penelitian ini didasarkan pada studi pendahuluan berupa observasi dan wawancara kepada pasien diruang rawat inap RSJD Dr. RM Soedjarwadi Klaten, dimana didapatkan hasil 41 dari 59 pasien mengatakan susah tidur, malas melakukan aktivitas, rasa bersalah, dan tidak ada semangat untuk menjalani hidup yang merupakan gejala depresi. Tujuan : Tujuan ini bertujuan untuk mengetahui pengaruh art therapy menggambar terhadap tingkat depresi pada pasien skizofreniadi RSJD Dr. Soedjarwadi Klaten Provinsi Jawa Tengah 2016. Metode : Jenis penelitian yang dilakukan adalah pre eksperimental dengan one group design pretest-postest. Populasi pada penelitian ini berjumlah 41. Sampel berjumlah 15 orang diambil dengan teknik Purposive Sampling. Analisis data menggunakan Wilcoxon Match Paired Test. Hasil : Hasil uji Wilcoxon Match Paired Tes tmenunjukan $\mathrm{p}<\alpha$, dengan $\alpha=0,05$ dan $\mathrm{p}=0,001$. Hasil penelitian menunjukan perubahan yang signifikan pada kategori depresi minimal, dari $66,66 \%$ responden sebelum diberikan art therapy menggambar menjadi 86,66\% setelah diberikan art therapy menggambar. Kesimpulan: Ada pengaruh art therapy menggambar terhadap tingkat depresi pada pasien skizofrenia di RSJD Dr. RM Soedjarwadi Kalten Provinsi jawa Tengah Tahun 2016. Saran : Disarankan bagi pihak RSJD Dr. RM Soedjarwadi Klaten Provinsi Jawa Tengah untuk mengaplikasikan art therapy menggambar pada pasien skizofrenia dengan depresi
\end{abstract}

Kata kunci : Depresi - Art therapy - Menggambar

\section{ABSTRACT}

Background: This research relied on an initial study in the from of observation and interview to the patients of in-patients ward of RSJD Dr. RM Soedjarwadi Klaten, where there were 41 out of 59 patients reported having difficulty in sleeping reluctant to do activity, feel guilty, and having no spirit to experience life which represent the symptom of depression. Objective: To determine the effect of drawing art therapy on level of depression in patients with schizophrenia at RSJD Dr. RM Soedjarwadi Klaten, Central Java in 2016. Methods: This research was one group pre experimental. The sample was 15 patients taken by using purposive sampling. Data was analyzed by using Wilcoxon Match Pair Test. Results: The Result of Wilcoxon Match Paired Test shows $p<\alpha$, with $\alpha=0,05$ and $p=0,001 \%$. It shows a significant change in the category of minimal depression, from 66,66\% of the respondents before given drawing art therapy becomes 86,66\% after given drawing art therapy. Conclusions: There is a influence of drawing art therapy on level of depression in patients with schizophrenia in RSJD Dr. RM Soedjarwadi Klaten, Central Java on July 2016. Suggestion: RSJD Dr. RM Soedjarwadi Klaten Central of Java is suggested to apply the drawing art therapy to schizophrenia patients with depression.

Keywords: Depression - drawing art therapy - Schizophrenia 


\section{PENDAHULUAN}

Skizofrenia adalah gangguan psikotik yang sifatnya merusak, melibatkan gangguan berfikir, persepsi, pembicaraan, emosional dan gangguan perilaku. Bunuh diri adalah penyebab umum kematian dimana penderita skizofrenia pernah mencoba bunuh diri satu kali seumur hidupnya. Tindakan bunuh diri yang sering terjadi pada penderita skizofrenia salah satu faktor resikonya adalah adanya gejala depresi berat pada pasien.

Hasil studi pendahuluan yang dilakukan pada 6 April 2016, di RSJD Dr. RM Soedjarwadi Klaten Provinsi Jawa Tengah, diperoleh data jumlah pasien dengan gangguan jiwa yang melakukan rawat inap adalah 563 orang dari bulan Januari Sampai Maret 2016 dengan presentasi 32\% dengan diagnosis skizofrenia atau sebanyak 178 orang. Populasi pada penelitian ini adalah pasien skizofrenia dengan depresi ringan dan sedang. Pasien yang mengalami skizofrenia pada bulan april yaitu sejumlah 59 orang. Hasil observasi dan wawancara dari 59 pasien skizofrenia ada 41 pasien yang mengatakan susah tidur, malas melakukan aktivitas, rasa bersalah, dan tidak ada semangat untuk menjalani hidup, yang berarti 41 tersebut mengalami gejala depresi.

\section{METODE PENELITIAN}

Jenis penelitian yang dilakukan adalah pre eksperimental dengan one group design pretest-postest. Populasi pada penelitian ini adalah pasien dengan skizofrenia di RSJD. DR. RM. Soedjarwadi Klaten Jawa berjumlah 41. Sampel berjumlah 15 orang diambil dengan teknik Purposive Sampling. Analisis data menggunakan Wilcoxon Match Paired Test. untuk mengetahui pengaruh art therapy menggambar terhadap tingkat depresi pada pasien skizofreniadi RSJD Dr. Soedjarwadi Klaten Provinsi Jawa Tengah.

\section{HASIL DAN PEMBAHASAN}

\section{Hasil}

a. Jenis Kelamin

Tabel 1.

Distribusi Frekuensi Responden Berdasarkan jenis Kelamin di RSJD Dr. RM Soedjarwadi Klaten Provinsi Jawa Tengah Juli Tahun 2016

\begin{tabular}{ccc}
\hline Jenis Kelamin & Frekuensi & Persentase (\%) \\
\hline Perempuan & 9 & 60 \\
\hline Laki-laki & 6 & 40 \\
\hline Total & 15 & 100
\end{tabular}

Sumber : Data primer terolah, 2016. 
b. Usia Responden

Tabel 2.

Distribusi Frekuensi Responden Berdasarkan Usia di RSJD Dr. RM Soedjarwadi Klaten Provinsi Jawa Tengah Juli

Tahun 2016

\begin{tabular}{ccc}
\hline $\begin{array}{c}\text { Usia Responden } \\
\text { Tahun }\end{array}$ & Frekuensi & Persentase (\%) \\
\hline $16-20$ & 3 & 20 \\
\hline $21-25$ & 0 & 0 \\
\hline $26-30$ & 4 & 26,66 \\
\hline $31-35$ & 5 & 33,33 \\
\hline $36-40$ & 1 & 6,66 \\
\hline $41-45$ & 2 & 13,33 \\
\hline Total & 15 & 100,0 \\
\hline
\end{tabular}

Sumber: Data primer terolah, 2016.

c. Pendidikan responden

Tabel 3.

Distribusi Frekuensi Responden Berdasarkan Tingkat Pendidikan di RSJD Dr. RM Soedjarwadi Klaten Provinsi Jawa Tengah Juli Tahun 2016

\begin{tabular}{ccc}
\hline $\begin{array}{c}\text { Pendidikan } \\
\text { Responden }\end{array}$ & Frekuensi & Persentase (\%) \\
\hline SD & 5 & 33,33 \\
\hline SMP & 4 & 26,66 \\
\hline SMA & 4 & 26,66 \\
\hline SMK & 2 & 13,33 \\
\hline Total & 15 & 100,0 \\
\hline
\end{tabular}

Sumber: Data primer terolah, 2016.

d. Pekerjaan

Tabel 4.

Distribusi Frekuensi Responden Berdasarkan Pekerjaan Responden di RSJD Dr. RM Soedjarwadi Klaten Provinsi Jawa Tengah Juli

Tahun 2016

\begin{tabular}{ccc}
\hline Pekerjaan & Frekuensi & Persentase (\%) \\
\hline Tidak bekerja & 4 & 26,66 \\
\hline Petani & 8 & 53,33 \\
\hline Buruh & 3 & 20 \\
\hline Total & 15 & 100,0 \\
\hline
\end{tabular}

Sumber: Data primer terolah, 2016 
e. Lama Rawat

Tabel 5.

Distribusi Frekuensi Responden Berdasarkan Lama Rawat Responden di RSJD Dr. RM Soedjarwadi Klaten Provinsi Jawa Tengah Juli

Tahun 2016

\begin{tabular}{ccc}
\hline Lama Rawat & Frekuensi & Persentase (\%) \\
\hline $5-13$ hari & 8 & 53,33 \\
\hline $14-22$ hari & 3 & 20 \\
\hline $23-33$ hari & 3 & 20 \\
\hline 34-43 hari & 1 & 6,66 \\
\hline Total & 15 & 100,0 \\
\hline
\end{tabular}

Sumber: Data primer terolah, 2016

f. Tingkat Depresi Sebelum dilakukan Art Therapy Menggambar

Tabel 6.

Distribusi Frekuensi Responden Berdasarkan Tingkat Depresi Sebelum dilakukan Art Therapy Menggambar di RSJD Dr. RM Soedjarwadi Klaten Provinsi Jawa Tengah Juli Tahun 2016

\begin{tabular}{ccc}
\hline Tingkat Depresi & Frekuensi & Persentase (\%) \\
\hline Depresi Minimal & 10 & 66,66 \\
\hline Depresi Sedang & 5 & 33,33 \\
\hline Depresi Berat & 0 & 0 \\
\hline Depresi Sangat Berat & 0 & 0 \\
\hline Total & 15 & 100,0
\end{tabular}

Sumber: Data primer terolah, 2016

g. Tingkat Depresi Sesudah dilakukan Art Therapy Menggambar

Tabel 7.

Distribusi Frekuensi Responden Berdasarkan Tingkat Depresi Sesudah Art Therapy Menggambar pada Pasien Skizofrenia di RSJD Dr. RM Soedjarwadi Klaten Provinsi Jawa Tengah Juli Tahun 2016

\begin{tabular}{ccc}
\hline Tingkat Depresi & Frekuensi & Persentase (\%) \\
\hline Depresi Minimal & 13 & 86,66 \\
\hline Depresi Sedang & 2 & 13,33 \\
\hline Depresi Berat & 0 & 0 \\
\hline Depresi Sangat Berat & 0 & 0 \\
\hline Total & 15 & 100,0 \\
\hline
\end{tabular}

Sumber: Data primer terolah, 2016 
i. Uji Wilcoxon Match Paired Test

Tabel 8.

Hasil Perhitungan Uji Wilcoxon Match Paired Test Frekuensi Tingkat

Depresi Sebelum dan Sesudah Art Therapy Menggambar di RSJD

Dr. RM Soedjarwadi Klaten Provinsi Jawa Tengah

Juli Tahun 2016

\begin{tabular}{c|c|c|c}
\hline Sumber Data & $\mathbf{Z}$ & $\mathbf{P}$ & Kesimpulan \\
\hline Pretest-Postest & $-3,436$ & 0,011 & $\mathrm{P}<\alpha$ \\
\hline
\end{tabular}

Sumber: Data primer terolah, 2016

Analisis: Berdasarkan tabel 8 pada halaman 4 didapatkan hasil uji statistik menggunakan Wilcoxon Match Paired Test menunjukan $\mathrm{p}$ sebesar 0,001 dengan $\alpha=0,05$, sehingga dapat disimpulkan bahwa H0 Ditolak dan $\mathrm{H} \alpha$ diterima yang berarti ada pengaruh antara art therapy menggambar terhadap tingkat depresi RSJD Dr. RM Soedjarwadi Klaten Provinsi Jawa Tengah Juli Tahun 2016.

\section{Pembahasan}

a. Jenis Kelamin

Didapatkan bahwa sebagian besar responden berjenis kelamin perempuan yaitu sebnayak 9 responden (60\%). Responden berjenis kelamin perempuan lebih rentan mengidap depresi dengan alasan perubahan hormonal dalam siklus menstruasi, berhubungan dengan kehamilan, kelahiran dan menopause yang membuat wanita lebih rentan mengidap depresi.

b. Usia

Sampel paling banyak didapatkan pada usia 31-35 tahun. Pada masa dewasa awal yaitu usia 20-35 tahun karakteristik umur tersebut adalah berbagai tanggung jawab finansial dan rumah tangga dengan pasangan hidup. Pada usia ini akan banyak muncul masalah-masalah pribadi maupun keluarga yang muncul sehingga membuat seorang individu merasa tertekan.

c. Tingkat pendidikan

Subjek penelitian paling banyak berpendidikan SD yaitu sebanyak 5 orang $(33,33 \%)$. Hal ini didukung oleh model depresi dari Stuart, Pendidikan merupakan salah satu sumber koping yaitu kemampuan personal dibidang pendidikan terkait dengan pengetahuan dan intelegensi seseorang.

d. Pekerjaan

Sebagian besar responden bekerja sebagai petani yaitu sebanyak 8 responden $(53,33 \%)$. Semakin sedikit pendapatan dan semakin berat beban ekonomi yang ditanggung maka peluang untuk mengidap depresi semakin tinggi.

e. Lama Dirawat

Sebagian besar subjek penelitian adalah responden yang dirawat selama 4 - 13 hari sebanyak 8 orang (53,33\%). Waktu dan lamanya seseorang terpapar stressor, akan memberikan dampak terhadap keterlambatan dalam mencapai 
kemampuan dan kemandirian. Tingkat depresi sebelum dilakukan art therapy menggambar'

f. Hasil tingkat depresi sebelum dilakukan art therapy menggambar

Responden dengan kategori depresi minimal sebanyak 10 responden $(66,66 \%)$ dan kategori depresi sedang sebanyak 5 responden $(33,33)$. Depresi merupakan gangguan alam perasaan ( $\mathrm{mood})$, yang ditandai dengan kemurungan dan kesedihan yang mendalam dan berkelanjutan sehingga hilanggnya kegairahan hidup, mengalami gangguan dalam menilai realitas ( Reality Testing Ability, masih baik), kepribadian tetap utuh atau tidak mengalami keretakan kepribadian (Splitting of personality), perilaku dapat terganggu tetapi dalam batas-batas normal.

g. Tingkat depresi sesudah dilakukan art therapy menggambar

Sesudah dilakukan art therapy menggambar frekuensi tingkat depresi dengan kategori minimal sebanyak 13 orang $(86,66 \%)$. Data ini menunjukan terjadi penurunan frekuensi depresi yang signifikan. Art therapy menggambar dapat mengatasi masalah dalam mengungkapkan perasaan, atau emosi dengan cara atau bahasa yang lain, tetapi juga dapat membantu individu dari segala usia mengekplorasi emosi, keyakinan, mengurangi stress, mengatasi masalah dan konflik, dan menimbulkan rasa nyaman.

h. Uji statistic Wilcoxon Match Paired Test Uji statistic Wilcoxon Match Paired Test menunjukan hasil yang bermakna dengan signifikasi $\mathrm{p}=0,001$ dengan $\alpha=0,05$. Data ini menunjukan $\mathrm{H} 0$ ditolak sehingga terjadi penurunan tingkat depresi setelah dilakukan art therapy menggambar. Rerata pretest 12,1333 dan posttest 9,8667 sehingga selisih rata-rata pretestpostest sebesar 2,2666. Hasil penelitian ini ada kaitannya dengan teori (Hirawan 2014), mengatakan bahwa art therapy menggambar adalah salah satu profesi dibidang kesehatan yang menggunakan aktivitas menggambar untuk mengatasi masalah dalam mengungkapkan perasaan, atau emosi dengan cara atau bahasa yang lain, tetapi juga dapat membantu individu dari segala usia mengplorasi emosi, keyakinan, mengurangi stress, mengatasi masalah konflik, dan menimbulkan rasa nyaman pada dirin klien.

\section{KESIMPULAN}

Sebagian besar responden di RSJD Dr. RM Soedjarwadi Klaten Provinsi Jawa Tengah berjenis kelamin perempuan. Sebagian besar responden berusia 31-35 tahun. Sebagian besar responden berpindidikan SD. Sebagian besar responden di bekerja sebagai petani. Sebagian besar responden dengan lama perawatan 4-13 hari. Sebagian besar responden sebelum dilakukan art therapy menggambar tingkat depresi minimal. Sebagian besar responden sesudah dilakukan art therapy menggambar tingkat depresi minimal. Dalam penelitian ini didapatkan hasil bahwa terdapat pengaruh art therapy menggambar terhadap tingkat depresi pada pasien skizofrenia di RSJD Dr. RM Soedjarwadi Klaten Provinsi Jawa Tengah. 


\section{SARAN}

1' Bagi RSJD Dr. RM Soedjarwadi Klaten

Art therapy menggambar dapat diaplikasikan sebagai terapi tambahan di RSJD Dr. RM Soedjarwadi Klaten Provinsi Jawa Tengah.

2. Bagi peneliti lain

Bagi peneliti selanjutnya diharapkan mengadakan penelitian lanjutan mengenai art therapy menggambar terhadap tingkat depresi pada klien dengan skizofrenia menggunakan kelompok kontrol.

\section{DAFTAR PUSTAKA}

Achir , Yani. (2013). Ilmu Pendidikan Psikologi. Jakarta:Rineka Cipta.

Ahmadi , Abu. (2013). Ilmu Pendidikan Psikologi. Jakarta:Rineka Cipta.

American Art Theraphy Association. (2007). The American Art Therapy Association's Mission . Diakses pada tanggal 18 Maret 2016 dari : http://arttherapy.org/ aata-aboutus/

Hawari, D, (2006). Manajemen Stres Cemas dan Depresi, Jakarta: Fakultas Kedokteran Universitas Indonesia.

Maramis, W.T dan Albert A. Maramis 2009. Catatan Ilmu Kedokteran Jiwa, Edisi. Surabaya: Airlangga University Pers.

Stuart, Laria.(2009). Keperawatan Jiwa. Edisi 3. Alih Bahasa Akhir Yani. Jakarta : EGC 